\title{
Cardiac tamponade and successful pericardiocentesis in an extremely low birth weight neonate with percutaneously inserted central venous line: a case report
}

\author{
Alfredo Pizzuti ${ }^{1}$, Emilia Parodi ${ }^{2}$, Paola Abbondi ${ }^{2}$, Mario Frigerio ${ }^{2}$
}

\begin{abstract}
Background: Pericardial effusion and cardiac tamponade are rare but life-threatening complications of percutaneosuly inserted central line (PICL) use in extremely low birth weight (ELBW) neonates, with an incidence reported between $0.07 \%$ and $2 \%$ of PICLs placement. Timely diagnosis and pericardiocentesis has been proven to be life-saving.

Case presentation: The patient was a $620 \mathrm{~g}$ birth weight neonate who presented with sudden cardiac instability 18 days after the insertion of a PICL and in spite of a presumed satisfactory position of the catheter tip. The transthoracic echocardiography demonstrated severe pericardial effusion with evidence of cardiac tamponade. Successful urgent subxiphoid pericardiocentesis was performed; totally $2 \mathrm{ml}$ of whitish fluid was collected, which resulted consistent to the composition of the hyperosmolar TPN solution infused.

Conclusion: Cardiac tamponade should be considered in any newborn with a peripherally inserted central catheter who presents with cardiorespiratory instability (bradycardia, cyanosis and metabolic acidosis), even when lines are believed to be placed correctly.
\end{abstract}

\section{Background}

Percutaneously inserted central lines (PICLs) are commonly used in neonatal intensive care units (NICU) to provide parenteral nutrition and medications for extremely low birth weight (ELBW) infants. PICLs have been associated with a number of device-specific complications (occlusion, infection, thrombosis, breakage, migration, displacement) including rare but life-threatening complications such as pericardial effusion and cardiac tamponade.

Incidence of pericardial effusion/cardiac tamponade has been previously reported in literature between $0.07 \%$ and $2 \%$ of PICLs placement [1-8]. Pericardial effusion may be more likely when the catheter tip is placed within the heart outline on X-ray examination; however,

\footnotetext{
* Correspondence: emilia.parodi@unito.it
${ }^{2}$ Neonatal Intensive Care Unit, Ordine Mauriziano Hospital, (Largo Turati n

* Correspondence: emilia.parodi@unito.it
${ }^{2}$ Neonatal Intensive Care Unit, Ordine Mauriziano Hospital, (Largo Turati n 62), Turin, (10128), Italy
} 62), Turin, (10128), Italy

positioning the tip outside the heart does not completely prevent it.

As timely diagnosis and pericaridocentesis has been proven to be life-saving, this complication should be considered in any newborn with an inserted central line who presents with cardiorespiratory instability.

We report the case of a successful pericardiocentesis performed in a ELBW neonate who presented with cardiac tamponade 18 days after the placement of a PICL.

\section{Case presentation}

A 620 g Caucasian female, was delivered at our Hospital after 25 weeks of gestation by caesarean section secondary to maternal congestive heart failure from dilated cardiomiopathy. Apgars were 9 and 9 at 1 and 5 minutes, respectively. She was intubated at birth and received surfactant. A 27 G polyurethane (PremiCath ${ }^{\mathrm{P}}$ ) central venous catheter was inserted through the right basilic vein on day 1 . Chest X-ray after insertion confirmed optimal positioning, the catheter tip being at the 
junction of inferior vena cava and right atrium. The neonate was mechanically ventilated for 14 days and then started nasal continuous positive airway pressure (CPAP) ventilation.

On day 18 the baby weight was $670 \mathrm{~g}$. She was still on CPAP with a $\mathrm{FiO}_{2}$ of 0.4 and a PEEP of $4 \mathrm{cmH}_{2} \mathrm{O}$. Arterial blood gas analysis showed good parameters (pH: 7.3, $\mathrm{pCO}_{2}$ : $56 \mathrm{mmHg}, \mathrm{PO}_{2} 39 \mathrm{mmHg}$ ), oxygen saturation values were stable (97\%). The neonate was on partial parenteral nutrition, receiving $50 \mathrm{ml}$ of formula milk and $36 \mathrm{ml}$ of parenteral nutrition administered via the peripheral venous route. Unexpectedly, at 10:30 p.m. the infant started presenting worse saturations (92-94\%) and her oxygen requirement increased form 0.4 to 0.6. At 12:00 p.m. she suddenly became pale, presented repeated and prolonged desaturations and needed to be ventilated. Despite an improvement in oxygen saturation immediately after positive-pressure ventilation (PPV) with bag and mask, the infant's clinical conditions worsened again and she needed to be reintubated. Chest Xray showed the catheter tip at the connection of the inferior vena cava with the right atrium and no lung opacities. Regardless of synchronized intermittent mandatory ventilation (SIMV) (PIP 18, PEEP 3, $\mathrm{FiO}_{2} 65 \%$, rate 38 , Ti 0.35 ), at 1.00 a.m. there was a sudden deterioration with cardiorespiratory instability: the oxygen requirement increased up to 0.9 and the baby developed bradycardia $(70 \mathrm{bpm})$. Brachial arterial pressure was not detectable. Lung auscultation revealed coarse crakles, while cardiac auscultation revealed "distant" heart sounds. Dopamine $(5 \mu \mathrm{g} / \mathrm{kg}$ per $\mathrm{min})$ and furosemide (1.2 mg "una tantum") were administered.

The transthoracic echocardiography demonstrated marked pericardial effusion with evidence of cardiac tamponade (additional file 1). Urgent periocardiocentesis was planned; in the meanwhile cardiac arrest ensued (additional file 2). Subxiphoid pericardiocentesis was immediately performed using a 22-gauge needle. Totally $2 \mathrm{ml}$ of milky fluid was collected (see additional file 3 ). Skin appearance of the neonate improved rapidly after the procedure, her vital signs immediately returned to normal and her oxygen requirement instantly decreased from 0.9 to 0.5 and after a few minutes to 0.35. Echocardiography ten minutes later showed increased contractility with partial resolution of the pericardial effusion (additional file 4). At 2.00 a.m. the PICL was pulled back into the subclavian vein and inotropic support could be discontinued; two hours later ventilatory parameters could be reset (PIP 20, PEEP 3, $\mathrm{FiO}_{2} 40 \%$, rate 40$)$.

The morning after the neonate's clinical conditions were stable and arterial blood gas analysis showed good parameters (pH: 7.4, $\mathrm{pCO}_{2}: 50 \mathrm{mmHg}, \mathrm{PO}_{2} 46 \mathrm{mmHg}$ ). Biochemical analysis of the obtained pericardial fluid showed it to be consistent with the composition of the hyperosmolar TPN solution the neonate was receiving through the catheter. Ecocardiography showed normal cardiac filling and contractility (additional file 5).

The subsequent clinical course of the baby was uneventful. One year follow up echocardiograms showed no re-accumulation of the fluid and normal cardiac filling and contractility.

\section{Conclusion}

In the case of this ELBW neonate with PICL who presented with cardiac tamponade, timely diagnosis and pericaridocentesis using echocardiography resulted successful. Our experience shows that basic echocardiography is an easily accessible bedside assessment tool that may be life-saving and that subxiphoid percutaneous approach for the dreinage of pericardial effusion is safe, effective and easily performed even in a ELBW neonate.

As an emergency treatment may be life saving, cardiac tamponade must be kept in mind as a cause of sudden deterioration of very low birth weight neonates and promptly diagnosed. In this case report, the complication occurred 18 days after the placement of the central line and in spite of a presumed satisfactory position of the catheter tip. Thus, cardiac tamponade should be considered in any newborn with a peripherally inserted central catheter who presents with sudden deterioration, even when lines are believed to be placed correctly.

\section{Consent}

Written informed consent was obtained from the parents of the patient for publication of this case reports and accompanying images and videos. A copy of written consent is available for review by the journal's Editor-inChief.

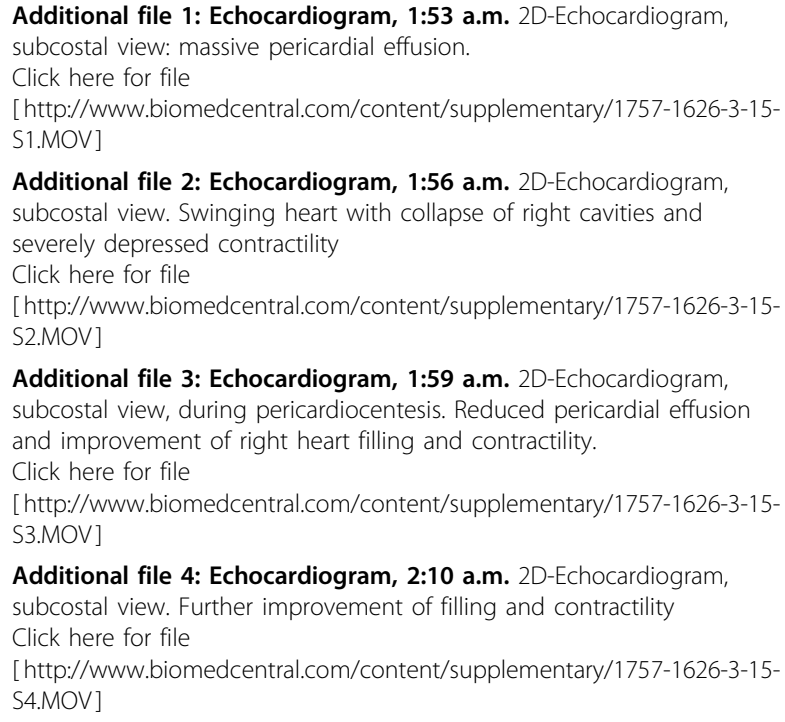

Additional file 3: Echocardiogram, 1:59 a.m. 2D-Echocardiogram, subcostal view, during pericardiocentesis. Reduced pericardial effusion and improvement of right heart filling and contractility.

Click here for file

[ http://www.biomedcentral.com/content/supplementary/1757-1626-3-15S3.MOV]

Additional file 4: Echocardiogram, 2:10 a.m. 2D-Echocardiogram, subcostal view. Further improvement of filling and contractility Click here for file

[http://www.biomedcentral.com/content/supplementary/1757-1626-3-15S4.MOV] 
Additional file 5: Echocardiogram, 8:28 a.m. 2D-Echocardiogram, subcostal view. Mild pericardial effusion with normal filling and contractility.

Click here for file

[http://www.biomedcentral.com/content/supplementary/1757-1626-3-15S5.MOV]

\section{Author details}

${ }^{1}$ Cardiology Unit, Ordine Mauriziano Hospital, (Largo Turati n 62), Turin, (10128), Italy. ${ }^{2}$ Neonatal Intensive Care Unit, Ordine Mauriziano Hospital, (Largo Turati n 62), Turin, (10128), Italy.

\section{Authors' contributions}

All authors contributed to acquisition of case details and the analysis and interpretation of them. EP wrote the first draft of the manuscript, AP and MF revised the manuscript.

All the authors have given final approval of this version to be published.

\section{Competing interests}

The authors declare that they have no competing interests.

Received: 30 November 2009

Accepted: 11 January 2010 Published: 11 January 2010

\section{References}

1. Nowlen TT, Rosenthal GL, Johnson GL, Tom DJ, Vargo TA: Pericardial effusion and tamponade in infants with central catheters. Pediatrics 2002, 110:137-142.

2. Beardsall $K$, White DK, Pinto EM, Kelsall AW: Pericardial effusion and cardiac tamponade as complications of neonatal long lines: are they really a problem?. Arch Dis Child Fetal Neonatal Ed 2003, 88:F292-295.

3. Menon G: Neonatal long lines. Arch Dis Child Fetal Neonatal Ed 2003, 88: F260-262.

4. Pettit J: Assessment of infants with peripherally inserted central catheters: Part 2. Detecting less frequently occurring complications. Adv Neonatal Care 2003, 3:14-26.

5. Pezzati M, Filippi L, Chiti G, Dani C, Rossi S, Bertini G, Rubaltelli FF: Central venous catheters and cardiac tamponade in preterm infants. Intensive Care Med 2004, 30:2253-2256.

6. Jouvencel P, Tourneux P, Perez T, Sauret A, Nelson JR, Brissaud O, Demarquez JL: [Central catheters and pericardial effusion: results of a multicentric retrospective study]. Arch Pediatr 2005, 12:1456-1461.

7. Forauer AR: Pericardial tamponade in patients with central venous catheters. J Infus Nurs 2007, 30:161-167.

8. Ohki Y, Yoshizawa Y, Watanabe M, Kuwashima M, Morikawa A: Complications of percutaneously inserted central venous catheters in Japanese neonates. Pediatr Int 2008, 50:636-639.

doi:10.1186/1757-1626-3-15

Cite this article as: Pizzuti et al:: Cardiac tamponade and successful pericardiocentesis in an extremely low birth weight neonate with percutaneously inserted central venous line: a case report. Cases Journal 2010 3:15.

Publish with Bio Med Central and every scientist can read your work free of charge

"BioMed Central will be the most significant development for disseminating the results of biomedical research in our lifetime. "

Sir Paul Nurse, Cancer Research UK

Your research papers will be:

- available free of charge to the entire biomedical community

- peer reviewed and published immediately upon acceptance

- cited in PubMed and archived on PubMed Central

- yours - you keep the copyright 